\title{
Curcumin exerts its tumor suppressive function via inhibition of NEDD4 oncoprotein in glioma cancer cells
}

\author{
XUE WANG $^{1}$, JIAOJIAO DENG $^{2}$, JINXIA YUAN $^{1}$, XIN TANG $^{2}$, YUELONG WANG $^{2}$, \\ HAIFENG CHEN $^{2}$, YI LIU ${ }^{2}$ and LIANGXUE ZHOU ${ }^{2}$ \\ ${ }^{1}$ School of Life Science, Shandong University, Jinan, Shandong 250100; ${ }^{2}$ Department of Neurosurgery \\ and State Key Laboratory of Biotherapy, West China Hospital, Sichuan University, and \\ Collaborative Innovation Center for Biotherapy, Chengdu, Sichuan 610041, P.R. China
}

Received January 26, 2017; Accepted March 30, 2017

DOI: $10.3892 /$ ijo.2017.4037

\begin{abstract}
Glioblastoma is the most common brain cancer in adults. It represents one of the top ten malignant tumors with an average survival time of nine months despite treatments with surgery, radiotherapy and chemotherapy. Curcumin is a phytochemical turmeric isolated from root of the Curcuma longa plant. Accumulating evidence have proved that curcumin targets numerous cancer signaling pathways. The E3 ubiquitin ligase NEDD4, neural precursor cell expressed developmentally downregulated protein 4 , is frequently overexpressed in various cancers. However, whether curcumin regulates NEDD4 expression has not been described in human cancers. Therefore, in this study, we explored the roles of NEDD4 in glioma cell proliferation, apoptosis and mobility. We further investigated whether curcumin exerts its antitumor activities via suppressing NEDD4 expression. We found that curcumin reduced the expression of NEDD4 and Notch1 and pAKT, leading to glioma cell growth inhibition, apoptosis, and suppression of migration and invasion. Moreover, deletion of NEDD4 expression enhanced the sensitivity of glioma cells to curcumin treatment. Thus, inactivation of NEDD4 by curcumin could be a promising approach for therapeutic intervention.
\end{abstract}

\section{Introduction}

Brain cancer has been proved as the leading cause of cancer death among children and adolescents (1). Cerebral glioma is the most common brain tumor in human, which represents one of the top ten malignant tumors (2). The principal

Correspondence to: Dr Yi Liu or Dr Liangxue Zhou, Department of Neurosurgery and State Key Laboratory of Biotherapy, West China Hospital, Sichuan University, and Collaborative Innovation Center for Biotherapy, Chengdu, Sichuan 610041, P.R. China

E-mail: neurosurgeon@live.cn

E-mail: liangxuezhousc@126.com

Key words: curcumin, glioma, NEDD4, invasion, apoptosis, proliferation features of glioma are strong angiogenesis and local invasive growth. It is often difficult to remove entire brain tumor by surgery. Glioblastoma secretes high levels of VEGF (vascular endothelial growth factor), which is responsible for the endothelial cell proliferation, blood-brain barrier permeability and angiogenesis $(3,4)$. Many chemotherapeutic drugs cannot pass the blood-brain barrier (5). Moreover, glioblastoma is aggressive and generally resistant to therapies including surgery, radiation, and conventional chemotherapy. Although treatment options have been greatly improved for glioma during the past decades, the morbidity and mortality rates are still at a high level, and the average survival time is nine months (6). Therefore, it is critical to discover molecular targets associated with the pathogenesis of glioma and find new therapeutic agents for the treatment of glioma.

Curcumin is a yellow-gold color phytochemical turmeric isolated from root of the Curcuma longa plant (7). Multiple biological properties have been identified for this compound, including anti-inflammatory, wound healing and antineoplastic capabilities (8-10). Regarding its anticancer activity, curcumin has been described as an inducer of apoptosis and cell cycle arrest via regulating multiple cancer signaling pathways, such as NF- $\mathrm{BB}$ (nuclear factor- $\kappa \mathrm{B}$ ), Ras, AKT, Notch1, Wnt/ $\beta$-catenin, FOXO1 (forkhead box protein 1), PI3K (phosphoinoside-3-kinase), and so on (11-16). It is of great interest to ascertain the molecular insight onto curcumin-mediated anticancer property.

The E3-ubiquitin ligase NEDD4, neuronal precursor cell-expressed developmentally downregulated 4-1, consists of an N-terminal C2, four WW domains and a catalytic C-terminal HECT domain. NEDD4 is responsible for substrate recognition in the poly-ubiquitination of proteins for degradation $(17,18)$. NEDD4 regulates many physiological progresses, such as the development of neuromuscular junction (19) and neurite (20). In addition, deregulation of NEDD4 expression was observed in ischemic stroke and neurodegeneration $(21,22)$. Notably, NEDD4-mediated protein poly-ubiquitination and degradation has been implicated in cancer development and is drawing increasing interest. It has been reported that NEDD4 is frequently overexpressed in a wide range of tumor types, such as non-small cell lung carcinomas (23), breast cancer (24), gastric carcinomas (25), 
and colorectal cancer (26). Wang et al discovered that NEDD4 promotes ubiquitin-mediated PTEN (phosphatase and tensin homologue) degradation, resulting in phosphoinositide 3-kinase (PI3K)/AKT signaling pathway activation and cell proliferation (27). They further found the reverse correlation between the expression level of PTEN and NEDD4 both in animal models and human cancer samples. NEDD4 exerts its oncogenic activities in a major type of gastric cancers and serves as an exceptional prognostic biomarker for gastric cardia adenocarcinoma and is functionally associated with metastasis (25). Studies also showed that NEDD4 is involved in FoxM1B (Forkhead box protein M1 isoform B)-induced immortalized human astrocytes transformation and GBM (glioblastoma multiforme) formation (28). Recently, NEDD4 was identified to promote migration and invasion of glioma cells through a ubiquitin-dependent proteolysis of CNrasGEFs (cyclic nucleotide-Ras guanine nucleotide exchange factors) (29). These data suggest that inactivation of NEDD4 could be an attractive approach for treatment of human cancers.

Here, we investigated the function of NEDD4 in glioma cell growth, apoptosis, migration and invasion. We further probed whether curcumin could suppress the expression of NEDD4 in glioma cells. Moreover, we aimed to determine the mechanistic role of NEDD4 in curcumin-induced glioma cell growth inhibition. Our findings could provide a therapeutic potential for treatment of patients with glioma.

\section{Materials and methods}

Cell culture and reagents. The SNB19 and A1207 human glioma cell lines were maintained in Dulbecco's modified Eagle's medium (DMEM MGC803; Gibco), supplemented with $10 \% \mathrm{FBS}$ and $100 \mathrm{U} / \mathrm{ml}$ penicillin/streptomycin (Hyclone) at $37^{\circ} \mathrm{C}$ in a humidified atmosphere $\left(5 \% \mathrm{CO}_{2} / 95 \%\right.$ air $)$. Primary antibodies for NEDD4 (\#2740s, 1:1,000), Notch1 (\#3608s, 1:1,000), and pAkt (\#13038, 1:1,000) were purchased from Cell Signaling Technology (Danvers, MA, USA). All secondary antibodies were purchased from Thermo Fisher Scientific. Monoclonal anti-tubulin (T9028, 1:5,000), curcumin (CAS no. 458-37-7, 99.5\% purity), and MTT (3-4,5-dimethyl2-thiazolyl-2, 5-diphenyl-2-H-tetrazolium bromide, CAS no. 57360-69-7) were purchased from Sigma-Aldrich (St. Louis, MO, USA). Curcumin was dissolved in DMSO to make a 30-mM stock solution and was added directly to the medium at different concentrations. TRIzol, Lipofectamine ${ }^{\mathrm{TM}} 2000$ and plus reagents were obtained from Invitrogen (Carlsbad, CA, USA). DMEM, penicillin/streptomycin, RevertAid First Strand cDNA Synthesis kit and SYBR ${ }^{\circledR}$ Select Master mix were obtained from Thermo Fisher Scientific (Waltham, MA, USA).

Cell proliferation assays. SNB19 and A1207 cells $\left(5 \times 10^{3}\right.$ cells/ well) were seeded in 96-well plates and cultured overnight. Then the cells were treated with different concentrations of curcumin for 48 and $72 \mathrm{~h}$. The cell proliferation was measured using MTT assays according to the manufacturer's protocols. Briefly, $10 \mu \mathrm{l}$ MTT solution $(0.5 \mathrm{mg} / \mathrm{ml})$ was added to each well, and the plates were incubated for $4 \mathrm{~h}$ in an incubator. The liquid supernatant was then removed and $100 \mu \mathrm{l}$ DMSO was added to each well. The absorbance was measured at $490 \mathrm{~nm}$ using the Multimode Reader of SpectraMax M5 (Moleucular
Devices, Sunnyvale, CA, USA). Independent experiments were repeated in triplicate.

Cell apoptosis analysis. Glioma cells were seeded at a density of $2 \times 10^{5}$ cells/well in 6-well plates. Various concentration of curcumin was added to each well. Cells were allowed to culture for $48 \mathrm{~h}$ and then harvested by centrifugation, subsequently resuspended in $500 \mu \mathrm{l}$ of binding buffer containing $5 \mu 1$ propidium iodide (PI) and $5 \mu 1$ Annexin V-FITC. The stained cells were analyzed using a FACSCalibur flow cytometer (BD Biosciences, USA).

Cell cycle assays. Glioma cells were cultured in 6-well plates at a density of $2 \times 10^{5}$ cells/well overnight. Curcumin was then added and allowed to incubate for another $48 \mathrm{~h}$. Cells were harvested and washed with PBS, suspended with $70 \%$ ice-cold alcohol and fixed overnight. Cells were then washed and suspended with $500 \mu 1$ PBS. Cells were incubated with $100 \mu \mathrm{g} / \mathrm{ml} \mathrm{RNase}$ and $50 \mathrm{mg} / \mathrm{ml} \mathrm{PI} \mathrm{(propidium} \mathrm{iodide)} \mathrm{at} 37^{\circ} \mathrm{C}$ for $30 \mathrm{~min}$. Cell cycle was determined with a FACScalibur flow cytometer (BD Biosciences).

Wound healing assay. After 72-h incubation, glioma cells grew to $90 \%$ confluence. A lesion on monolayers was created with a sterile $100-\mu 1$ pipette tip. Debris was removed by carefully washing with PBS. Cells were cultured for the designated time course. Images were captured at the lesion border using an inverted microscope (Olympus, IX71).

Cell invasion assay. Cell invasive capacity was performed using Transwell chamber ( $8-\mu \mathrm{m}$ pore size, Corning), according to the manufacturer's instructions. Briefly, filters were precoated with $100 \mu \mathrm{l}$ of Matrigel (BD Biosciences) diluted with serum-free medium to the final concentration of $1 \mathrm{mg} / \mathrm{ml}$. Suitable amount of pretreated cell suspension in serum-free DMEM was added into the upper chamber. Medium $(600 \mu \mathrm{l})$ containing $10 \%$ FBS was then added into the bottom chamber. After 20 -h incubation at $37^{\circ} \mathrm{C}$, the non-invasive cells in the upper chamber were removed. The invaded cells on filters were stained with Giemsa. The stained cells in each filter were captured and counted in at least six randomly-selected images.

Quantitative real-time reverse transcription-PCR $(Q-P C R)$ analysis. The total RNA was extracted with TRIzol(Invitrogen) and reversed-transcribed into cDNA by RevertAid First Strand cDNA Synthesis kit. Real-time Q-PCR was performed using Power SYBR Green PCR Master Mix and the results were calculated by $2^{-\Delta \Delta C t}$ method. The primers for NEDD4 were as follows: sense, 5'-GCT GCT AAA GGT CTC TGG TGT-3'; antisense, 5'-AGG CTT AGA TTC TGC AAC TTG-3'. Primers for GAPDH: sense, 5'-ACC CAG AAG ACT GTG GAT GG-3'; antisense, 5'-CAG TGA GCT TCC CGT TCA G-3'.

Transient transfection of plasmids and small interfering RNAs (siRNAs). Transfection of glioma cells with pcDNA3.1NEDD4 and NEDD4 siRNAs was performed by using the Lipofectamine 2000 transfection reagent, according to the manufacturer's instructions. All the transfections were performed three times independently. The siRNA sequences that targeting human NEDD4 are: Sense, 5'-GGA GAA UUA 

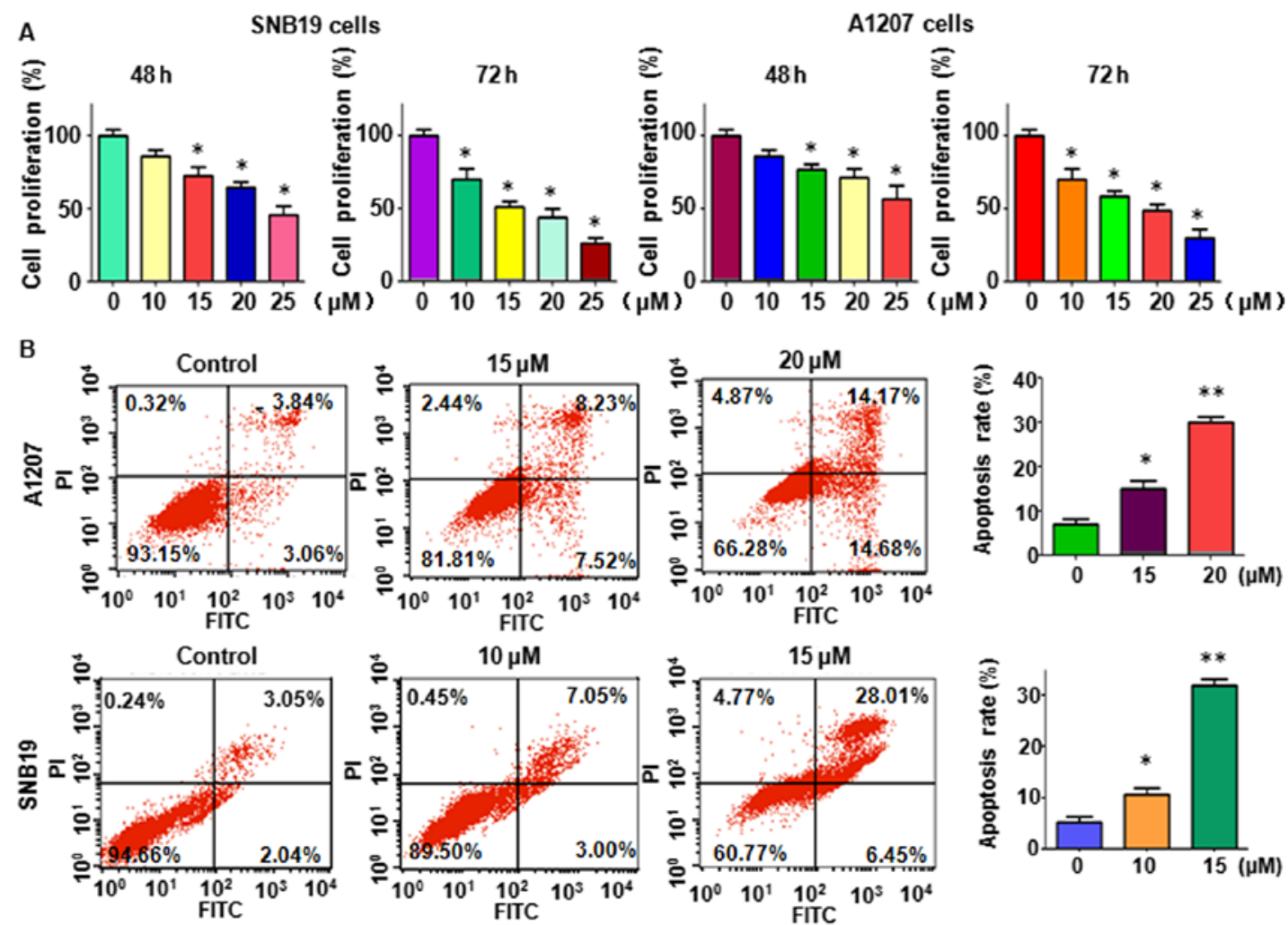

$c$
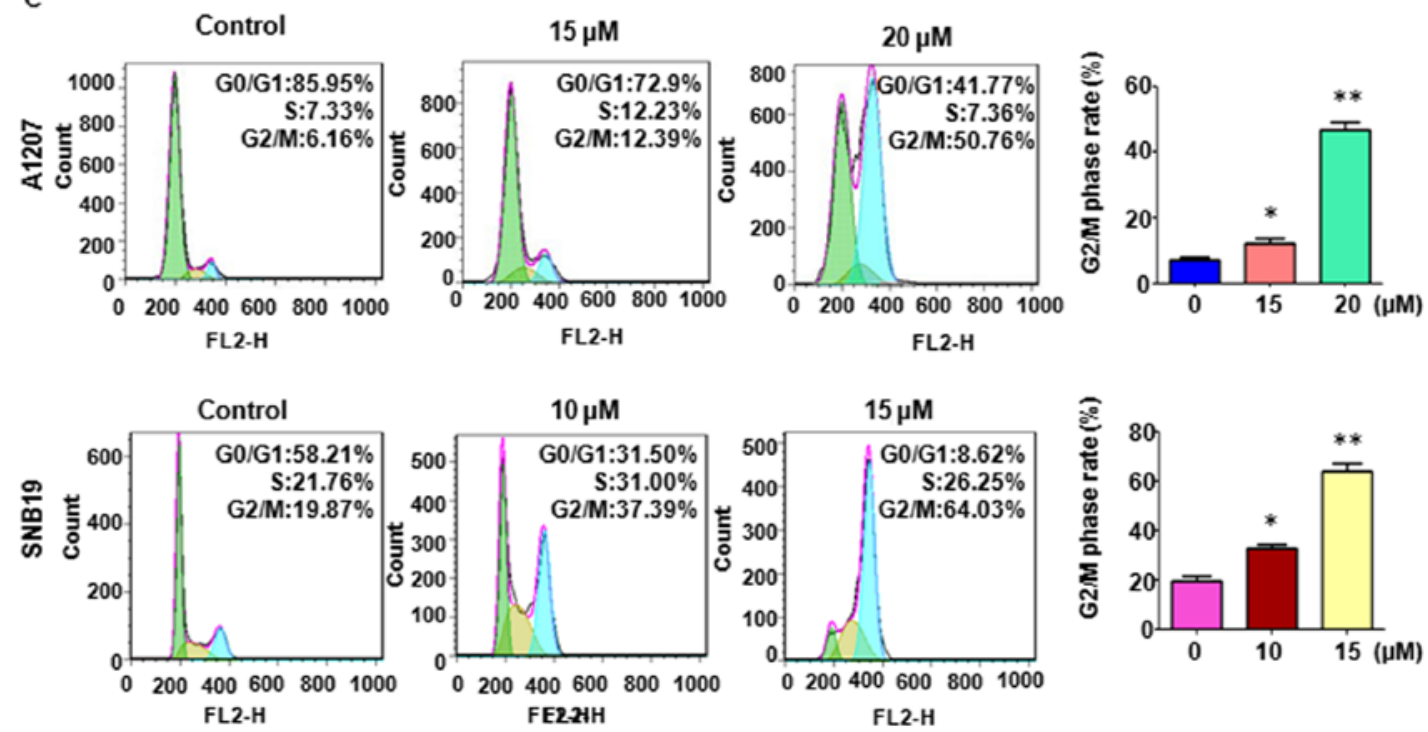

Figure 1. Curcumin inhibits glioma cell proliferation, induces apoptosis and cell cycle arrest. (A) Glioma cells viability was detected after treatment with curcumin for 48 and $72 \mathrm{~h}$, respectively, using MTT assay. ${ }^{*} \mathrm{P}<0.05$, compared to the control groups treated with DMSO. (B) Left panel, curcumin-induced glioma cell apoptosis was accessed by flow cytometry. Right panel, quantitative results are illustrated for apoptosis. "P<0.05, ${ }^{* *} \mathrm{P}<0.01$ vs control. (C) Left panel, curcumin-triggered glioma cell cycle arrest was measured by flow cytometry. Right panel, quantitative results are illustrated for G2/M phase. " $\mathrm{P}<0.05$, ${ }^{* *} \mathrm{P}<0.01$ vs control.

\section{UGG GUG UCA ATT-3'; antisense, 5'-UUG ACA CCC AUA AUU CUC CTT-3'.}

Western blot analysis. Pretreated glioma cells were harvested and lysed in cell lysis buffer supplemented with protease inhibitors. Protein concentrations were quantified using a BCA protein assay kit. Equal amount of denatured protein samples were separated by SDS-PAGE electrophoresis and then transferred onto a PVDF membrane. PVDF membranes were blocked with $5 \%$ non-fat milk and then incubated with primary antibody at $4^{\circ} \mathrm{C}$ overnight. After washing with TBST three times, the membranes were incubated with second antibody at room temperature for $\sim 1 \mathrm{~h}$. The expression of target proteins was detected by electrochemiluminescence (ECL).

Statistical analysis. All data were conducted using GraphPad Prism 4.0 (GraphPad Software, La Jolla, CA, USA) and were expressed as mean \pm SD of triplicate determinants. Statistical significance was evaluated using ANOVA and differences with a $\mathrm{P}<0.05$ were considered statistically significant. 
A
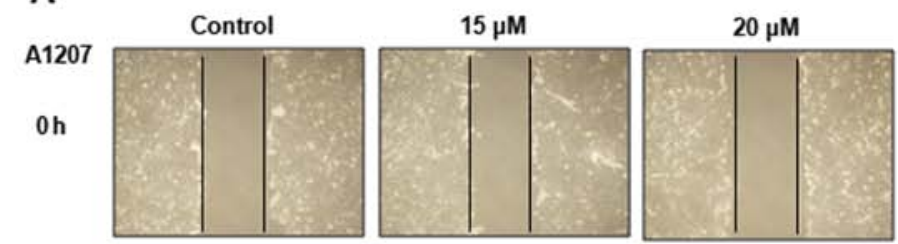

$20 \mathrm{~h}$
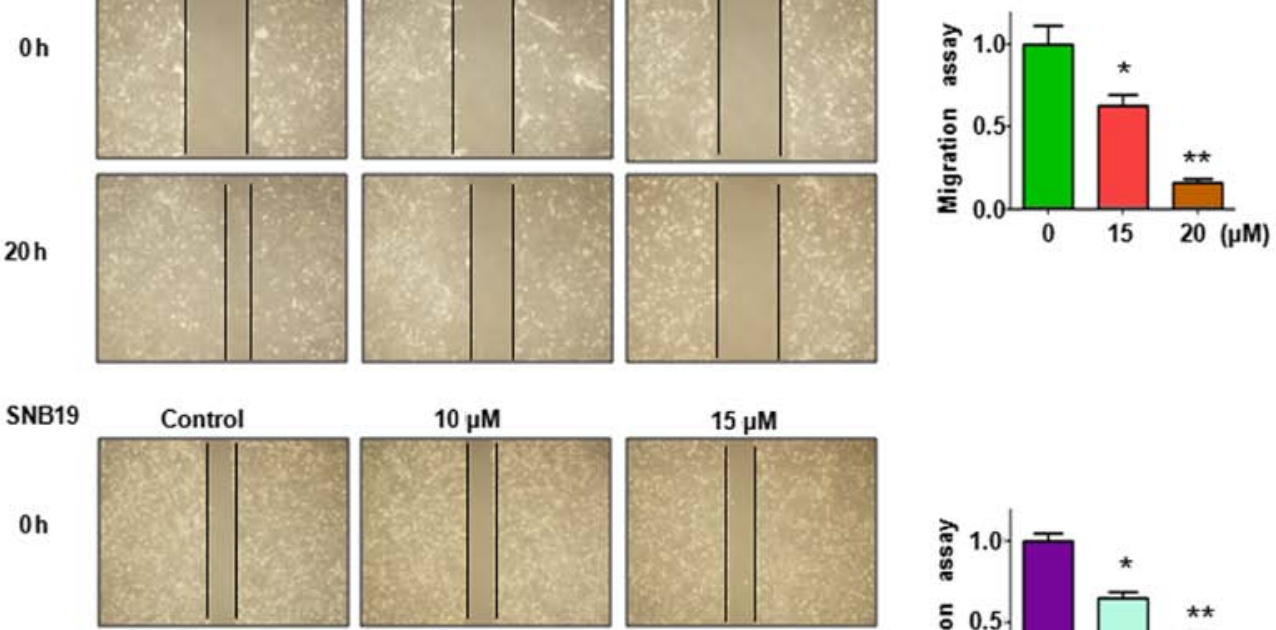

$10 \mathrm{~h}$
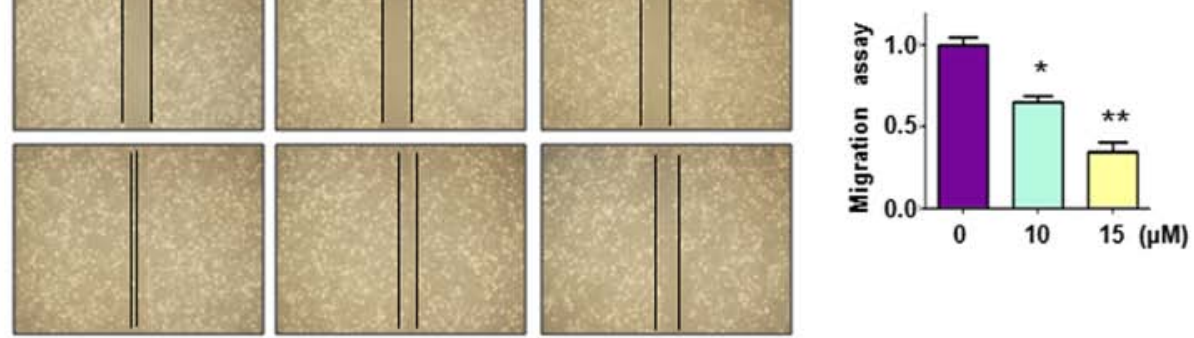

B
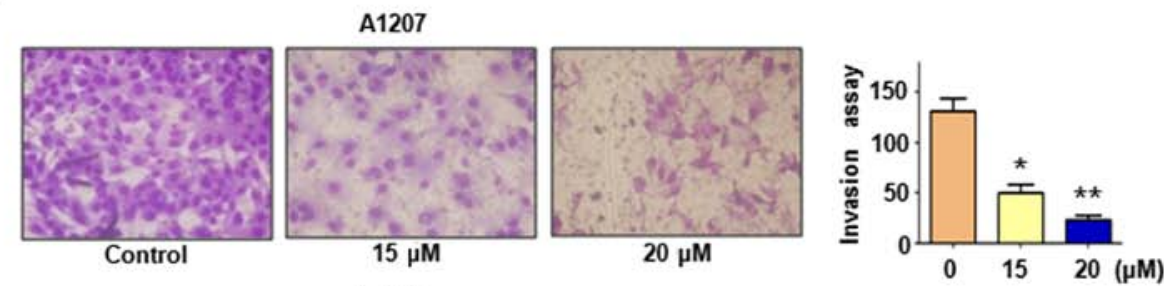

SNB19

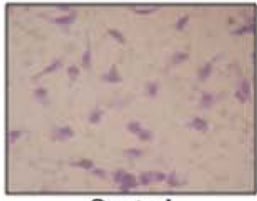

Control
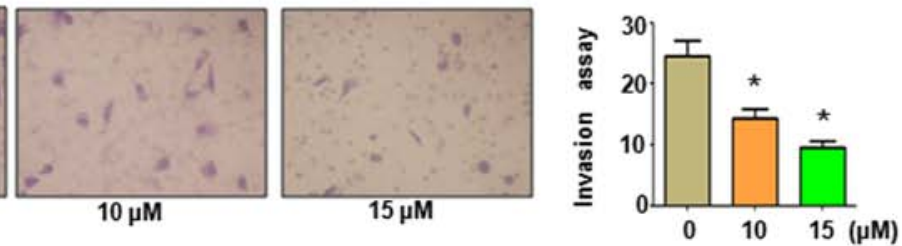

Figure 2. Inhibitory effects of curcumin on glioma cell migration and invasion. (A) Left panel, the inhibitory effect of curcumin on glioma cell migration was detected using wound healing assay in A1207 cells and SNB19 cells treated with curcumin. Right panel, quantitative results are illustrated for the left panel. ${ }^{*} \mathrm{P}<0.05,{ }^{* *} \mathrm{P}<0.01$ vs control. (B) Left panel, the inhibitory effect of curcumin on glioma cell invasion was measured by Transwell chambers assay. Right panel, quantitative results are illustrated for left panel. ${ }^{*} \mathrm{P}<0.05,{ }^{* * *} \mathrm{P}<0.01$ vs control.

\section{Results}

Curcumin inhibits glioma cell proliferation. Curcumin has been reported to inhibit cell growth in numerous human cancers. In this study, glioma cells were treated with different concentrations of curcumin for 48 and $72 \mathrm{~h}$, respectively. MTT assays were performed to detect whether curcumin exerts anti-proliferation in SNB19 and A1207 glioma cells. The MTT results showed that curcumin inhibited glioma cell growth in a time- and dose-dependent manner (Fig. 1A). Our results clearly proved that curcumin exhibited its anti-proliferation activity in glioma cells.

Curcumin promotes apoptosis of glioma cells. It has been reported that curcumin caused cell proliferation inhibition partly due to increased apoptosis. Then we determined whether curcumin could promote cell apoptosis in glioma cells. Annexin V-FITC/PI apoptosis assay was conducted in SNB19 and A1207 glioma cells treated with curcumin for $48 \mathrm{~h}$. Flow cytometer results showed that curcumin triggered glioma cell apoptosis in a dose-dependent manner (Fig. 1B). For instance, 15 and $20 \mu \mathrm{M}$ cucumin treatments led to apoptosis from $6.9 \%$ of control group to 15.75 and $28.85 \%$ in A1207 cells (Fig. 1B). Similar increased apoptosis by curcumin treatment was observed in SNB19 cells. Our results indicated that curcumin triggered glioma cell apoptosis.

Curcumin induced cell cycle arrest. To further determine the mechanism of curcumin-induced anti-proliferation in glioma cells, cell cycle analysis was conducted by PI staining and flow cytometry in both glioma cells after curcumin treatment. We observed that curcumin arrested cell cycle at G2/M phase in 
A

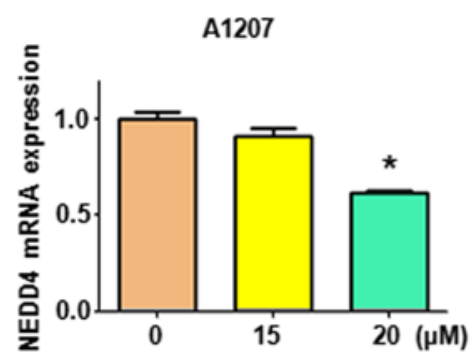

B

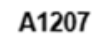

$\begin{array}{lllll}0 & 15 & 20 & \mu \mathrm{M}\end{array}$

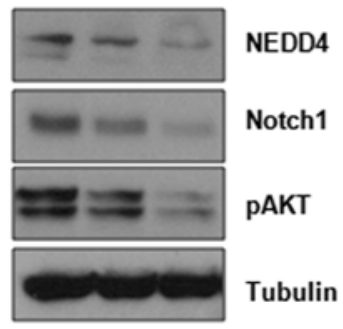

C
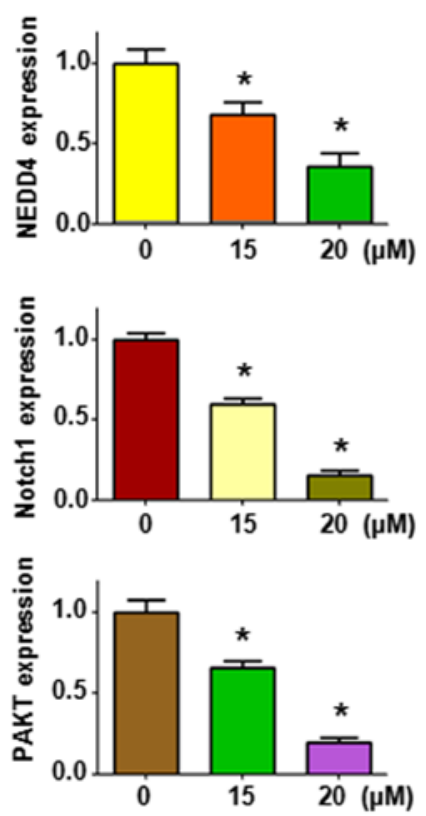

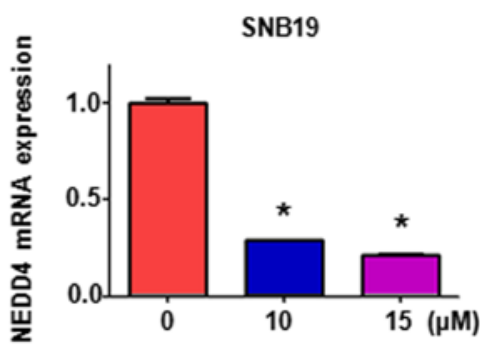

SNB19
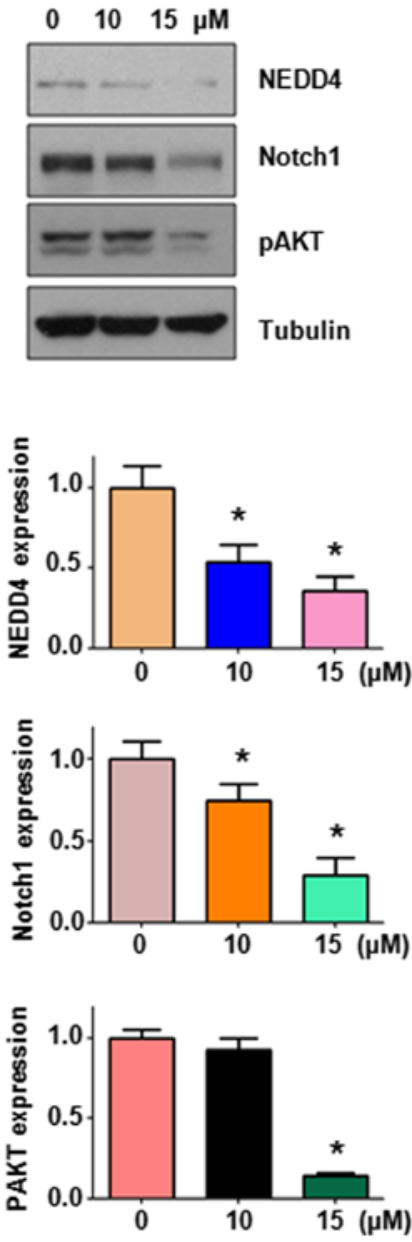

Figure 3. Curcumin suppresses NEDD4 expression at both mRNA and protein levels. (A) The mRNA expression of NEDD4 was measured by real-time RT-PCR in curcumin-treated glioma cells. (B) Alteration of NEDD4, Notch1 and pAkt expression levels was detected by western immunoblot analysis in curcumin-treated glioma cells. (C) Quantitative results are illustrated for the above immunoblotting images (B). * $\mathrm{P}<0.05$ vs control.

both glioma cell lines (Fig. 1C). For instance, $20 \mu \mathrm{M}$ curcumin treatment caused $\mathrm{G} 2 / \mathrm{M}$ phase from $6.16 \%$ in control group to $50.76 \%$ in $\mathrm{A} 1207$ cells (Fig. 1C). In line with this, $15 \mu \mathrm{M}$ curcumin led to increased G2/M phase from 19.87 to $64.03 \%$ in SNB19 cells (Fig. 1C). These results suggest that curcumin arrested cell cycle at $\mathrm{G} 2 / \mathrm{M}$ phase in glioma cells.

Curcumin inhibits cell migration and invasion in glioma cells. To examine the effect of curcumin on glioma cell motility, wound healing and Transwell assays were performed in both A1207 and SNB16 cells, respectively. Cell migration was significantly inhibited by curcumin treatment in both glioma cells (Fig. 2A). Moreover, invasion ability of glioma cells was also suppressed by curcumin (Fig. 2B). Our results demonstrated that curcumin could inhibit cell glioma cell motility abilities.

Curcumin suppressed NEDD4 expression in glioma cells. Since NEDD4 has been demonstrated to be a key oncoprotein in tumorigenesis, we hypothesized that NEDD4 may also be involved in the curcumin-mediated inhibition of cell growth and invasion in glioma cells. Q-PCR and western blot analysis were performed to measure the expression levels of NEDD4 after 48-h treatment of curcumin in both A1207 and SNB16 cell lines. As shown in Fig. 3A, NEDD4 mRNA levels were downregulated in A1207 and SNB19 cells in the presence of 
A
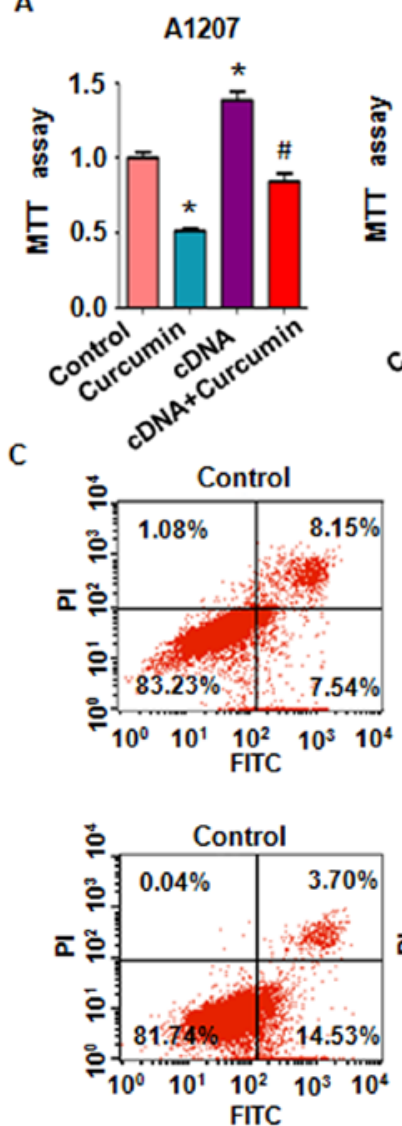

SNB19
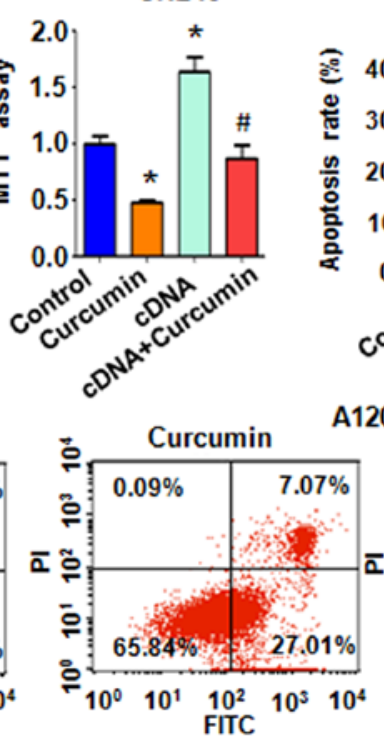

SNB19

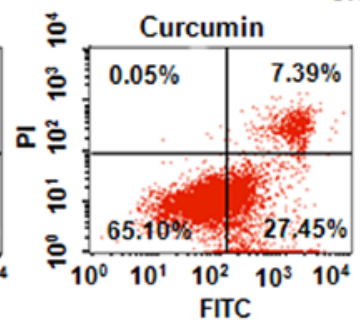

B
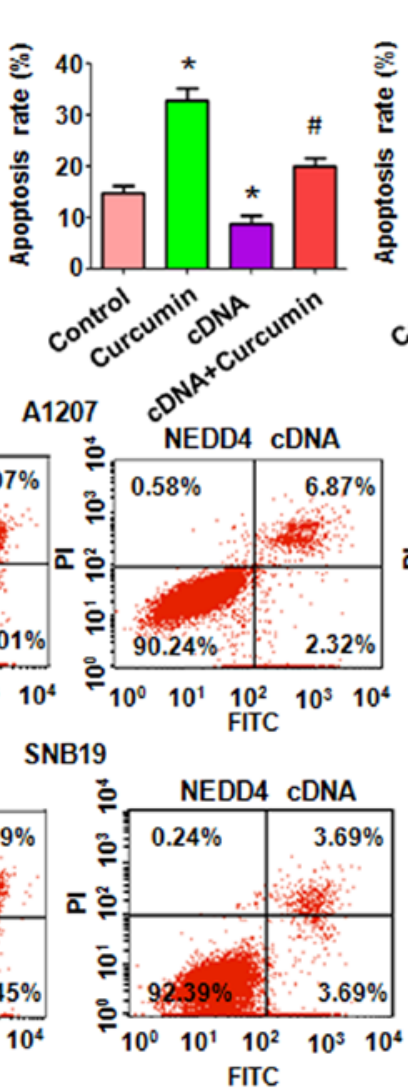

SNB19
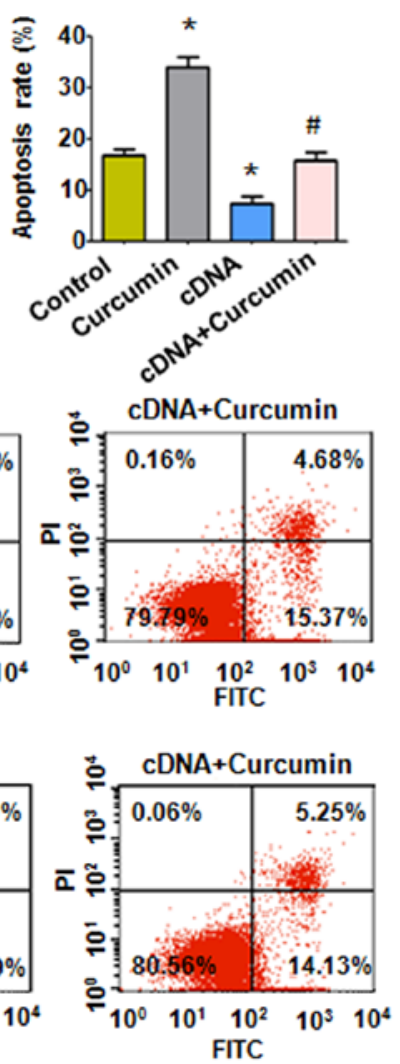

D

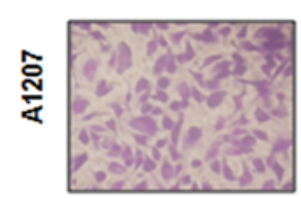

Control

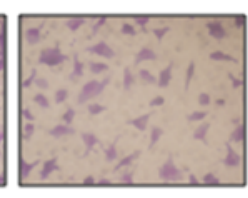

Curcumin
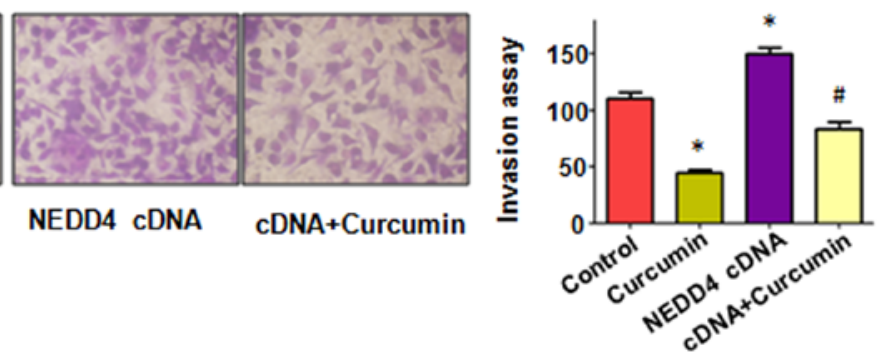

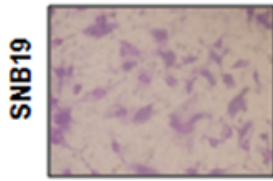

Control

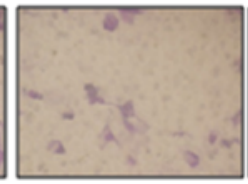

Curcumin
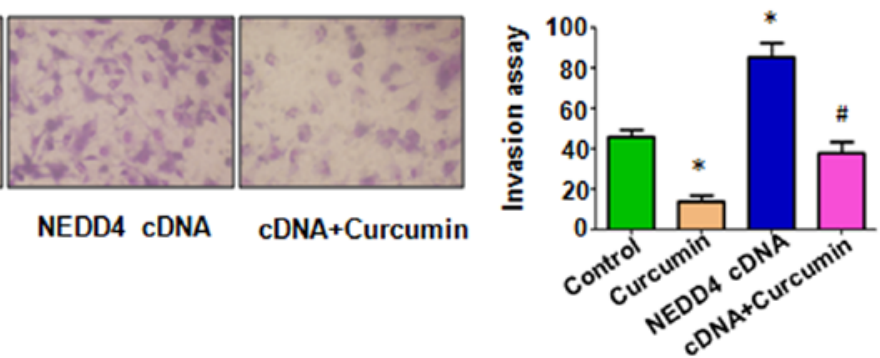

Figure 4. Overexpression of NEDD4 enhances glioma cell proliferation, suppresses cell apoptosis and increases cell invasion. (A) Glioma cell growth was measured by MTT assay after NEDD4 overexpression in combination with $15 \mu \mathrm{M}$ curcumin treatment for $72 \mathrm{~h}$. ${ }^{*} \mathrm{P}<0.05$, vs control; ${ }^{\#} \mathrm{P}<0.05$ vs curcumin treatment or NEDD 4 cDNA transfection. (B and C) Apoptotic cells were accessed by flow cytometry after NEDD4 overexpression in combination with $15 \mu \mathrm{M}$ curcumin treatment for $48 \mathrm{~h} .{ }^{*} \mathrm{P}<0.05$, vs control; ${ }^{*} \mathrm{P}<0.05$ vs curcumin treatment or NEDD4 cDNA transfection. (D) Cell invasion were detected by Transwell chamber assay after NEDD4 overexpression in combination with $15 \mu \mathrm{M}$ curcumin treatment for $20 \mathrm{~h}$. ${ }^{*} \mathrm{P}<0.05$, vs control; " $\mathrm{P}<0.05$ vs curcumin treatment or NEDD4 cDNA transfection.

curcumin. Subsequently, western blot analysis revealed that NEDD4 protein levels were significantly suppressed after a diluted concentration of curcumin treatment (Fig. 3B and C). In agreement with our hypothesis, NEDD4 was involved in the cytotoxic effect of curcumin on glioma cells. We further validated whether the suppression of NEDD4 by curcumin could affect the downstream targets of NEDD4. We examined the alterations of Notch1 and pAKT proteins in the presence of curcumin in glioma cells. The results showed that curcumin markedly downregulated the expression of Notch1 and pAKT 


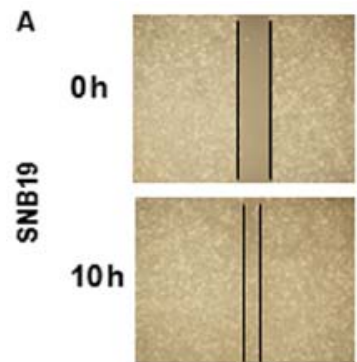

Control

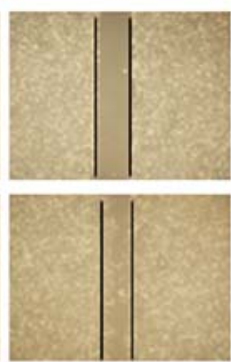

Curcumin

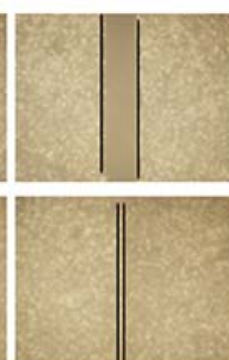

NEDD4 cDNA

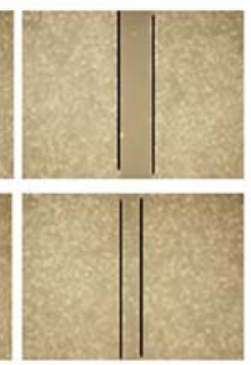

Both

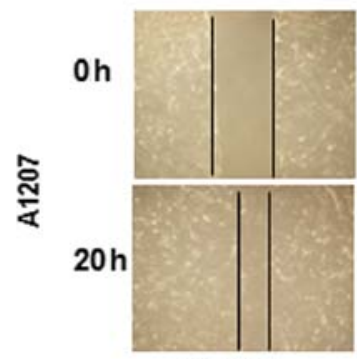

Control

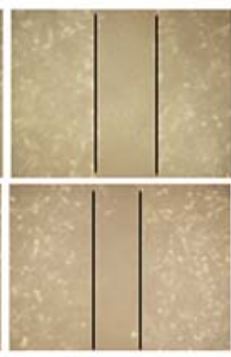

Curcumin

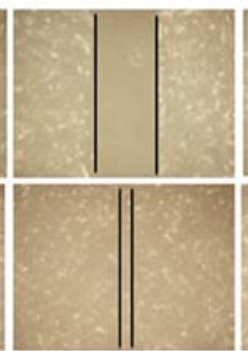

NEDD4 cDNA

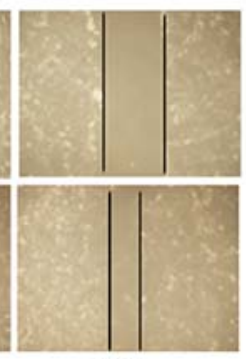

Both

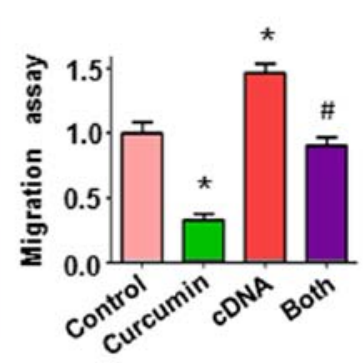

B

SNB19

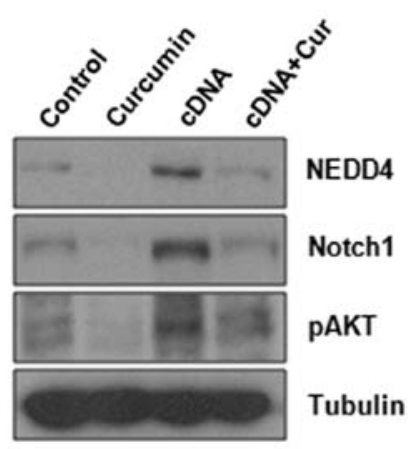

A1207

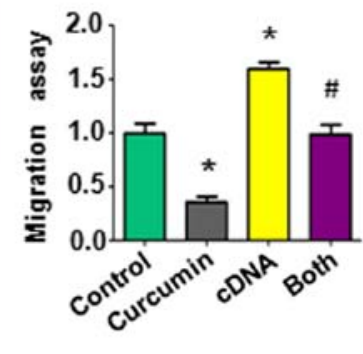

Figure 5. Overexpression of NEDD4 triggers glioma cell migration. (A) Left panel, the migration viability of glioma cells after NEDD4 cDNA transfection and $15 \mu \mathrm{M}$ curcumin treatment was measured by wound healing assay. Right panel, quantitative results are illustrated for the left panel. ${ }^{*}<0.05$, vs control; ${ }^{\#} \mathrm{P}<0.05$ vs curcumin treatment or NEDD4 cDNA transfection. (B) The expression of NEDD4, Notch1 and pAkt was detected in NEDD4 cDNA transfected glioma cells treated with $15 \mu \mathrm{M}$ curcumin for $48 \mathrm{~h}$.

in both glioma cell lines (Fig. 3B and C). Taken together, our findings supported that curcumin reduced the expression of NEDD4 in glioma cells.

Overexpression of NEDD4 promotes cell proliferation. To further determine whether the expression of NEDD4 was associated with the curcumin-induced cytotoxic effect on glioma cells, the overexpression of NEDD4 by its plasmid was performed. Glioma cells were transfected with NEDD4 cDNA or empty vector as control in the presence of curcumin. MTT assay showed that NEDD4 overexpression significantly promoted glioma cell proliferation, and curcumin-induced cell growth inhibition was partly blocked (Fig. 4A). The results from Annexin V-FITC/PI apoptosis assay showed that NEDD4 overexpression significantly decreased apoptosis in both glioma cell lines and annulled curcumin-induced apoptosis (Fig. 4B and C). We also investigated the effect of NEDD4 overexpression on cellular invasive and migratory properties of glioma cells. Transwell assay showed that overexpression of NEDD4 enhanced the invasion abilities of glioma cells (Fig. 4D). Notably, NEDD4 overexpression rescued curcumininduced cell invasion suppression to a certain degree (Fig. 4D). Moreover, we observed an increased migration of glioma cells after NEDD4 cDNA transfection, using wound healing assay (Fig. 5A). Consistently, NEDD4 overexpression abolished curcumin-caused cell mobility inhibition. We then detected the protein levels of Notch1 and pAKT. We found that transfection of NEDD4 cDNA significantly induced Notch1 and pAKT level in both glioma cell lines (Fig. 5B). Strikingly, curcumin-induced Notch1 and pAKT level suppression was partially abolished by NEDD4 cDNA transfection (Fig. 5B). These results provide evidence that curcumin exhibits antitumor activity in glioma cells through regulation of NEDD4 and Notch1 and pAKT.

Silence of NEDD4 by siRNA transfection sensitizes glioma cells to curcumin treatment. Furthermore, we examined whether co-transfection of NEDD4 siRNA enhanced curcumin- 


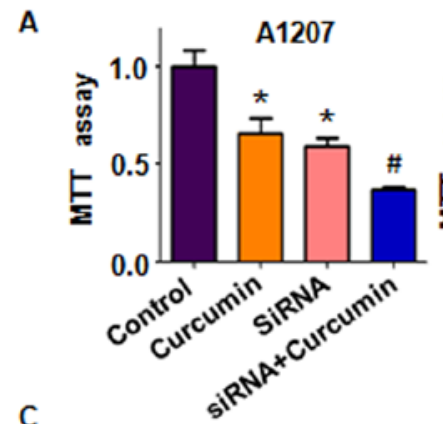

C
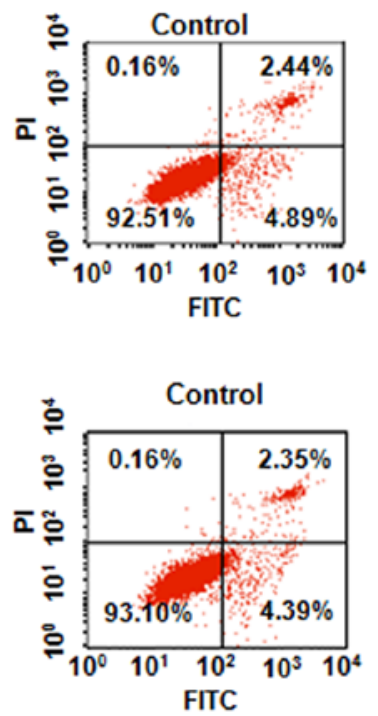
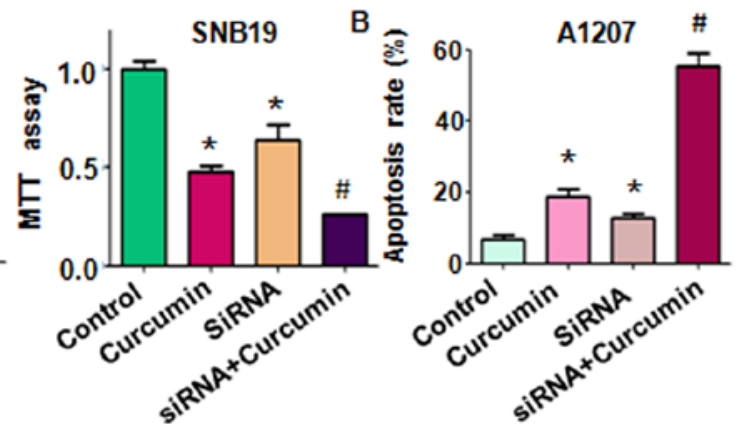

A1207
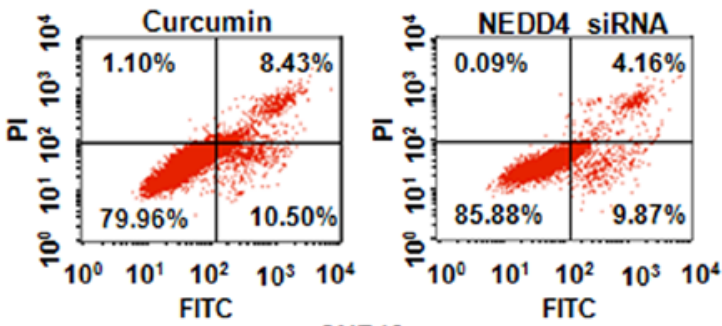

SNB19
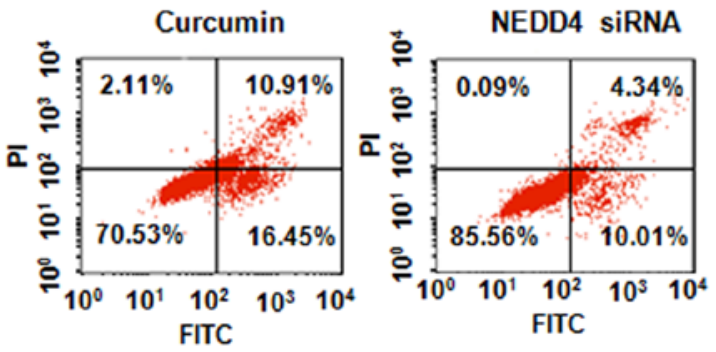

SNB19 \#

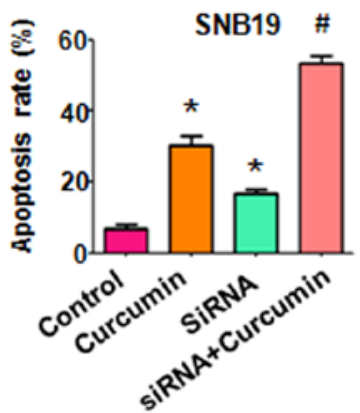

D
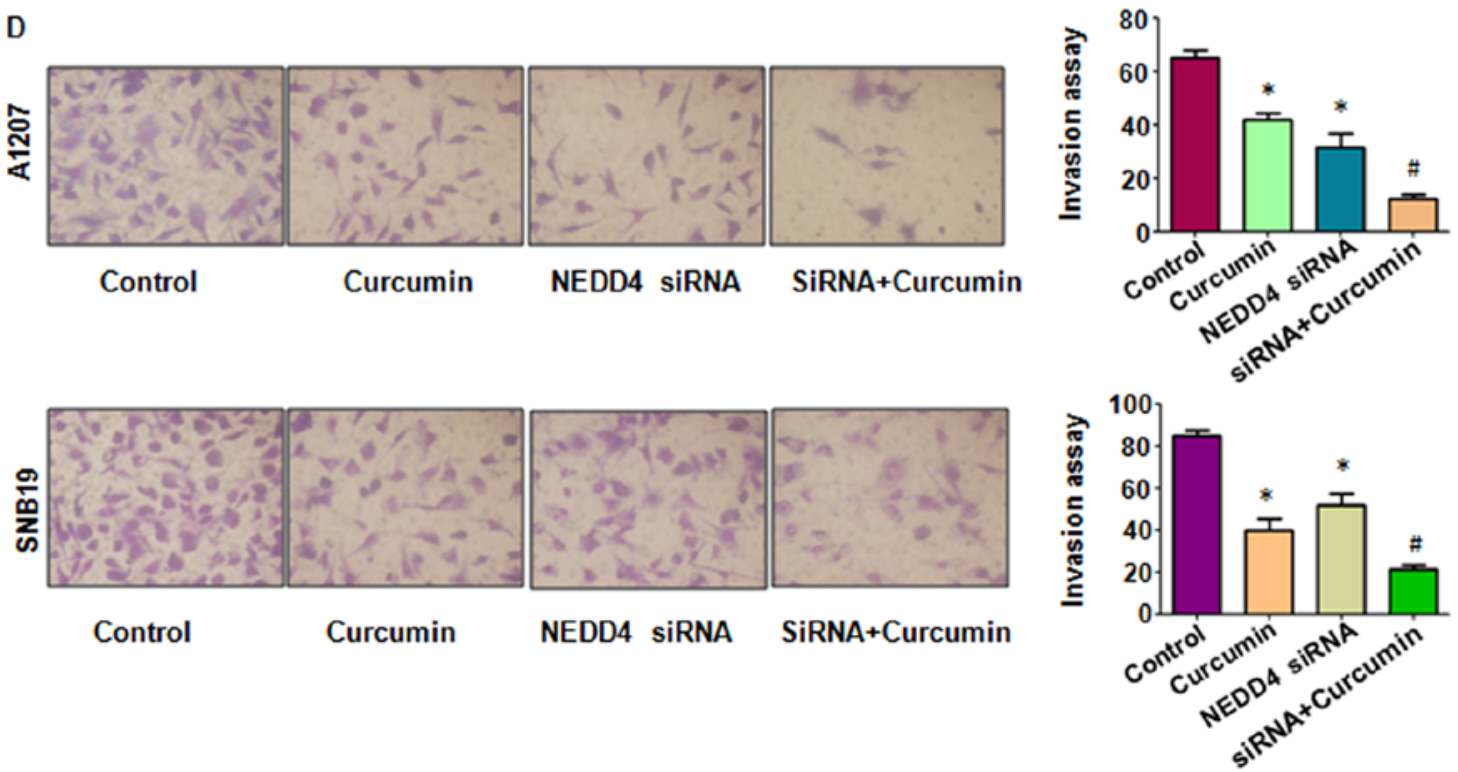

Figure 6. Knockdown of NEDD4 inhibits glioma cells proliferation, increased cell apoptosis and represses cell invasion. (A) MTT assay was performed to detect the effect of NEDD4 downregulation in combination with $15 \mu \mathrm{M}$ curcumin treatment on glioma cell growth for $72 \mathrm{~h}$. " $\mathrm{P}<0.05$, vs control; " $\mathrm{P}<0.05$ vs curcumin treatment or NEDD4 siRNA transfection. (B and C) Apoptotic cells were detected by flow cytometry in glioma cells after NEDD4 siRNA transfection and $15 \mu \mathrm{M}$ curcumin treatments for $48 \mathrm{~h}$. ${ }^{*} \mathrm{P}<0.05$, vs control; ${ }^{*} \mathrm{P}<0.05$ vs curcumin treatment or NEDD4 siRNA transfection. (D) Invasive cells were counted by Transwell chamber assay after NEDD4 siRNA transfection and $15 \mu \mathrm{M}$ curcumin treatment for $20 \mathrm{~h}$. ${ }^{*} \mathrm{P}<0.05$, vs control; ${ }^{*} \mathrm{P}<0.05$ vs curcumin treatment or NEDD4 siRNA transfection.

mediated tumor suppressive function. We found that glioma cells proliferation was markedly suppressed after NEDD4 siRNA silencing (Fig. 6A). The combination of curcumin with NEDD4 depletion strengthened cell viability inhibition to a greater degree than curcumin alone or siRNA transfection alone. Next, we found that NEDD4-silenced glioma cells 

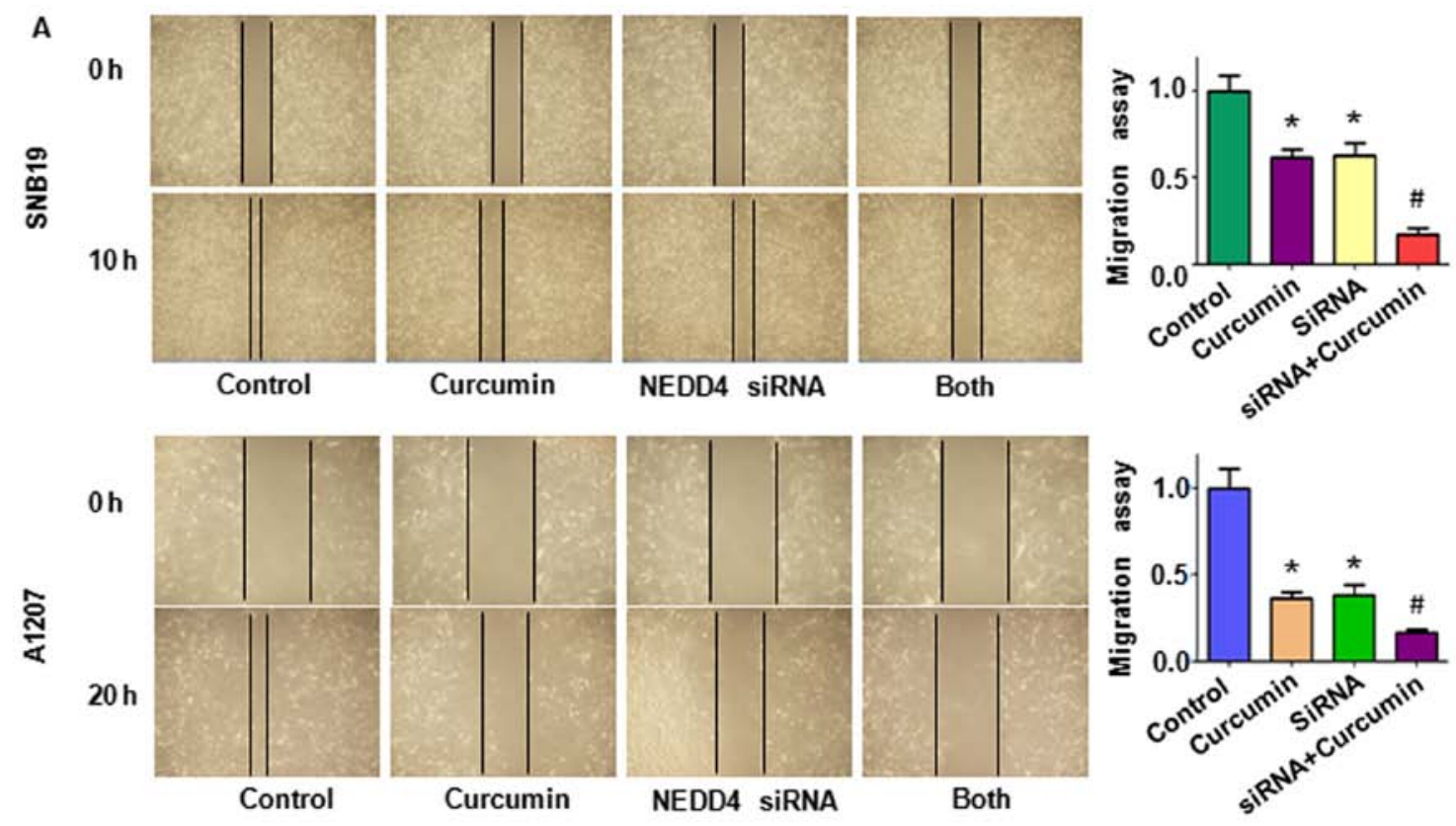

Both
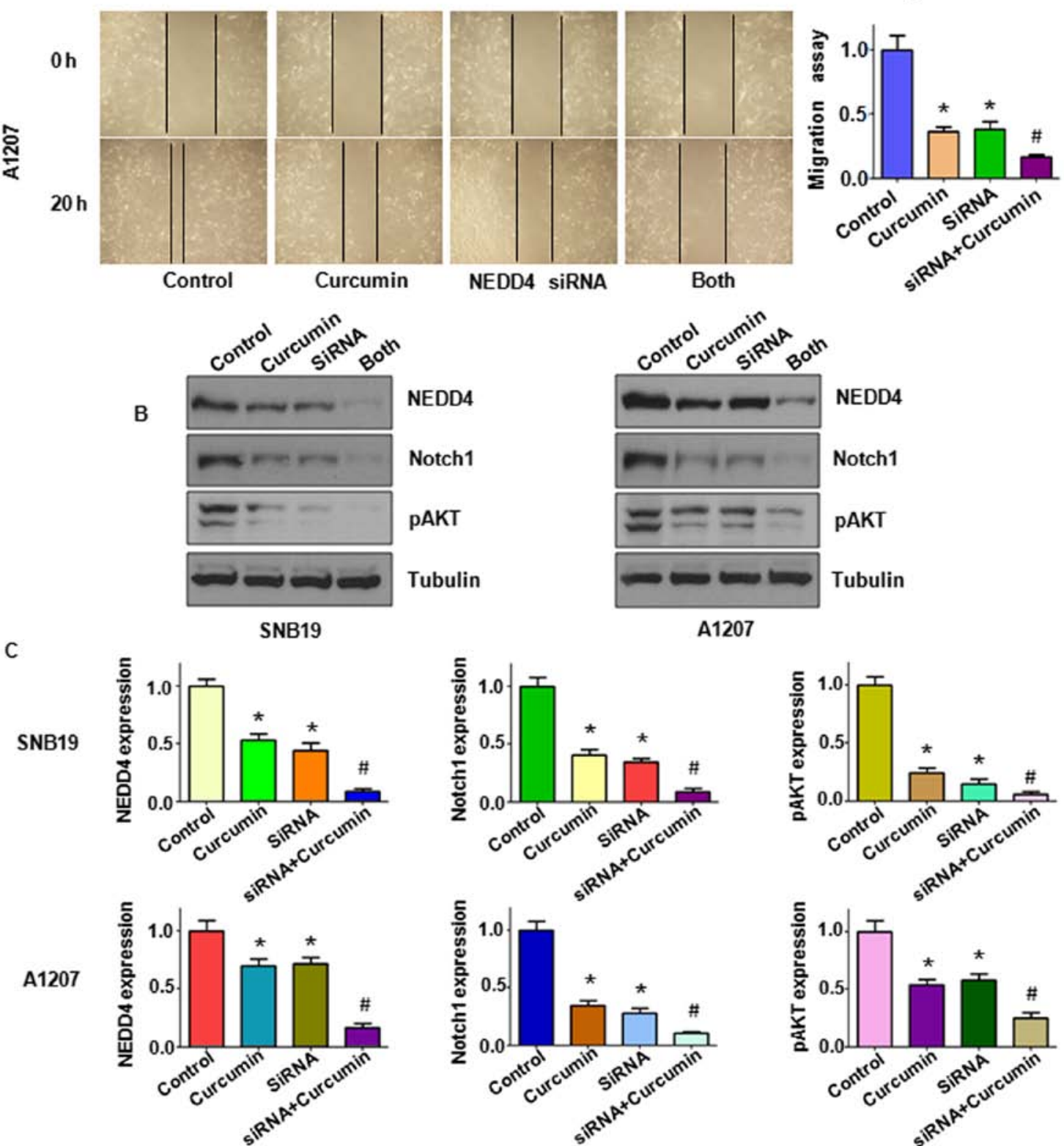

A1207
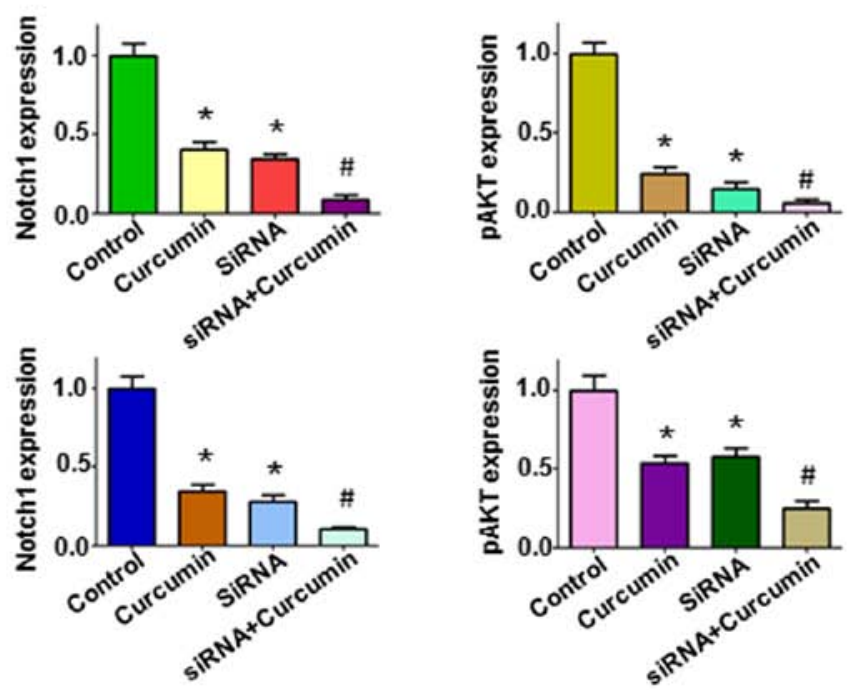

Figure 7. Knockdown of NEDD4 inhibits glioma cell migration. (A) Wound healing assay was performed to detect the alterations of glioma cell migration after NEDD4 downregulation and $15 \mu \mathrm{M}$ curcumin treatment. (B) The expression of NEDD4 and its targets Notch1 and pAkt were measured by western blotting in NEDD4 siRNA transfected glioma cells treated with $15 \mu \mathrm{M}$ curcumin for $48 \mathrm{~h}$. (C) Quantitative results are illustrated for the top panel. "P<0.05, vs control; ${ }^{\text {"}} \mathrm{P}<0.05$ vs curcumin treatment or NEDD4 siRNA transfection.

were markedly sensitive to spontaneous and curcumin-induced apoptosis (Fig. 6B and C). Thereafter, we also observed that downregulation of NEDD4 significantly suppressed cellular invasive and migratory abilities of glioma cells (Figs. 6D and 7A). More importantly, NEDD4 silence together with curcumin treatment disturbed cell invasion and migration rate to a higher degree. Subsequently, we found that downregulation of NEDD4 decreased the expression of Notch1 and pAKT after siRNA silencing of NEDD4 in both glioma cell lines (Fig. 7B and C). These results indicated that NEDD4 is involved in 
curcumin-mediated cell growth inhibition, apoptosis, invasion and mobility suppression in glioma cells.

\section{Discussion}

Curcumin is used in complementary oncology as it influences cell cycle arrest, proliferation, and apoptosis in a variety of cancers (30). It has been reported for its pleiotropic effects on cellular signaling pathways (10). Recently, curcumin was determined to sensitize human gastric cancer cells to 5 -fluorouracil through inhibition of the NF- $\mathrm{BB}$ survival signaling pathway (31). In pancreatic cancer cells, curcumin suppressed cell growth, inhibited mobility, and induced apoptosis via downregulating YAP and TAZ expression and subsequently suppressed Notch-1 expression (32). Curcumin inactivated FoxM1 and induced human acute myeloid leukemia (AML) growth inhibition, enhanced angiogenesis and chemosensitivity (33). Interestingly, Lim and colleagues recently demonstrated that curcumin is conductive to the COP9 signalosome 5-mediated ubiquitination and degradation of PD-L1 (programmed cell death-ligand 1) and as a result sensitized cancer cells to anti-CTLA4 therapy (34). The potential application value of curcumin in neural tumors was supported by previous studies, which showed the antitumor activity of this natural compound in vitro and in vivo (35-39). It was reported that transcription of the p21 (Waf1/Cip1) gene is activated by Egr-1 (early growth response-1) in response to curcumin treatment (39). Curcumin exerts anti-proliferative, anti-migratory, and anti-invasive properties against malignant gliomas via decreasing p-STAT3, c-Myc and proliferation marker Ki-67 (40). Wang et al found that curcumin suppresses glioma cell growth and invasion and induces apoptosis by downregulation of Skp2 (S-phase kinase associated protein 2) pathway (41). It was also reported that curcumin suppresses the SHH (Sonic Hedgehog)/GLI1 signaling pathway, and microRNA-326 enhances the chemo-sensitivity of glioma cells to curcumin in vitro and in vivo $(42,43)$. In this study, we found that curcumin exerts its antitumor activities via downregulation of NEDD4/Notch1 signaling.

NEDD4 has been reported to play an oncogenic role in tumor cell growth. NEDD4 is frequently overexpressed in a wide variety of tumors. Early studies revealed that, as an E3-ubiquitin ligase, NEDD4 promotes ubiquitination and subsequent degradation of PTEN, enhances cell proliferation by activating PI3K/AKT signaling pathway (27). In gastric cardia adenocarcinoma (GCA), NEDD4 is overexpressed in major GCA tumors, while knockdown of NEDD4 in gastric cancer cell lines markedly inhibited the gastric cancer cell migration and invasion (25). On account of its oncogenic role in GCA, NEDD4 could serve as an exceptional prognostic biomarker for GCA. Recently, NEDD4 was reported to target CNrasGEF-mediated decitabine invasion-promoting activity in MGC803 gastric cancer cells (44). In glioma cells, NEDD4 facilitates migration and invasion of U251 and U87 cells through triggering CNrasGEF, but has no effects on glioma cell proliferation and apoptosis (29). Studies also showed that overexpression of FoxM1B upregulates NEDD4 in immortalized human astrocytes, leading to cellular transformation and full malignant phenotype formation (28). Increased expression of important molecules for tumor growth, such as survivin, cyclin D1, and cyclin E, were also observed in immortalized human astrocytes. In the present study, we found that overexpression of NEDD4 in A1207 and SNB19 glioma cell lines enhanced cell growth, whereas the elimination of NEDD4 expression by curcumin treatment or siRNA silencing inhibited glioma cell proliferation. Deletion of NEDD4 expression enhanced the sensitivity of glioma cells to curcumin treatment. Moreover, we observed that overexpressed NEDD4 enhanced cell migration and invasion in both glioma cells. On the contrary, deletion of NEDD4 retarded glioma cell motility. Taken together, our data showed that NEDD4 is involved in regulation of cell proliferation, migration and invasion in A1207 and SNB19 glioma cells.

In conclusion, due to the oncogenic property of NEDD4 in glioma, inactivation of NEDD-1 by natural compounds or other small molecule inhibitors could be a promising approach for therapeutic intervention. Although curcumin exerts its antitumor activities in a variety of human cancers, it is worth noting that the therapeutic application of curcumin is restricted due to its poor absorption and unsatisfactory pharmacokinetics (45). Hence, it is necessary to search for new formulation solutions and synthesize novel curcumin analogues to improve the biopotency and to overcome the blood-brain barrier. Importantly, glioma mouse models are required to determine whether curcumin exhibits its antitumor activities via suppressing the NEDD4 signaling. Ubiquitin ligases have attracted great attention as potential therapeutic targets $(46,47)$. One compound, heclin (HECT ligase inhibitor) was recently described to inhibit a range of HECT ligases in vitro and kill growing cells by prolonged exposure (48). However, to obtain successful small molecule inhibitors of NEDD4, the complexity of the ubiquitin system and target specificity should be considered.

\section{Acknowledgements}

This study was supported by National Natural Sciences Foundation of China (81372446) and National S\&T Major Project (2013ZX09301304-007).

\section{References}

1. Siegel RL, Miller KD and Jemal A: Cancer statistics, 2016. CA Cancer J Clin 66: 7-30, 2016.

2. Aibaidula A, Lu JF, Wu JS, Zou HJ, Chen H, Wang YQ, Qin ZY, Yao Y, Gong Y, Che XM, et al: Establishment and maintenance of a standardized glioma tissue bank: Huashan experience. Cell Tissue Bank 16: 271-281, 2015.

3. Mentlein R, Forstreuter F, Mehdorn HM and Held-Feindt J: Functional significance of vascular endothelial growth factor receptor expression on human glioma cells. J Neurooncol 67 : 9-18, 2004

4. Kaur B, Khwaja FW, Severson EA, Matheny SL, Brat DJ and Van Meir EG: Hypoxia and the hypoxia-inducible-factor pathway in glioma growth and angiogenesis. Neuro-oncol 7: 134-153, 2005.

5. Walbert $\mathrm{T}$ and Chasteen K: Palliative and supportive care for glioma patients. Cancer Treat Res 163: 171-184, 2015.

6. Alifieris C and Trafalis DT: Glioblastoma multiforme: pathogenesis and treatment. Pharmacol Ther 152: 63-82, 2015.

7. Singh S: From exotic spice to modern drug? Cell 130: 765-768, 2007.

8. SreedharR, Arumugam S, Thandavarayan RA, Karuppagounder V and Watanabe K: Curcumin as a therapeutic agent in the chemoprevention of inflammatory bowel disease. Drug Discov Today 21: 843-849, 2016. 
9. Aggarwal BB and Sung B: Pharmacological basis for the role of curcumin in chronic diseases: An age-old spice with modern targets. Trends Pharmacol Sci 30: 85-94, 2009.

10. Rahmani AH, Al Zohairy MA, Aly SM and Khan MA: Curcumin: A potential candidate in prevention of cancer via modulation of molecular pathways. BioMed Res Int 2014: 761608, 2014.

11. Kasi PD, Tamilselvam R, Skalicka-Wozniak K, Nabavi SF, Daglia M, Bishayee A, Pazoki-Toroudi $\mathrm{H}$ and Nabavi SM: Molecular targets of curcumin for cancer therapy: An updated review. Tumour Biol 37: 13017-13028, 2016.

12. Bimonte S, Barbieri A, Leongito M, Piccirillo M, Giudice A, Pivonello C, de Angelis C, Granata V, Palaia R and Izzo F: Curcumin anticancer studies in pancreatic cancer. Nutrients 8: 8, 2016.

13. Zhao Z, Li C, Xi H, Gao Y and Xu D: Curcumin induces apoptosis in pancreatic cancer cells through the induction of forkhead box O1 and inhibition of the PI3K/Akt pathway. Mol Med Rep 12: 5415-5422, 2015.

14. Pattanayak R, Basak P, Sen S and Bhattacharyya M: Interaction of KRAS G-quadruplex with natural polyphenols: A spectroscopic analysis with molecular modeling. Int J Biol Macromol 89: 228-237, 2016.

15. Bortel N, Armeanu-Ebinger S, Schmid E, Kirchner B, Frank J, Kocher A, Schiborr C, Warmann S, Fuchs J and Ellerkamp V: Effects of curcumin in pediatric epithelial liver tumors: Inhibition of tumor growth and alpha-fetoprotein in vitro and in vivo involving the NFkappaB-and the beta-catenin pathways. Oncotarget 6: 40680-40691, 2015 .

16. Kasdagly M, Radhakrishnan S, Reddivari L, Veeramachaneni DN and Vanamala J: Colon carcinogenesis: Influence of Western dietinduced obesity and targeting stem cells using dietary bioactive compounds. Nutrition 30: 1242-1256, 2014

17. Maspero E, Mari S, Valentini E, Musacchio A,Fish A,Pasqualato S and Polo S: Structure of the HECT:ubiquitin complex and its role in ubiquitin chain elongation. EMBO Rep 12: 342-349, 2011.

18. Zou X, Levy-Cohen G and Blank M: Molecular functions of NEDD4 E3 ubiquitin ligases in cancer. Biochim Biophys Acta 1856: 91-106, 2015.

19. Liu Y, Oppenheim RW, Sugiura Y and Lin W: Abnormal development of the neuromuscular junction in Nedd4-deficient mice. Dev Biol 330: 153-166, 2009.

20. Moore G, Collins A, Brand C, Gold M, Lethborg C, Murphy M, Sundararajan V and Philip J: Palliative and supportive care needs of patients with high-grade glioma and their carers: A systematic review of qualitative literature. Patient Educ Couns 91: 141-153, 2013.

21. Lackovic J, Howitt J, Callaway JK, Silke J, Bartlett P and Tan SS Differential regulation of Nedd4 ubiquitin ligases and their adaptor protein Ndfip1 in a rat model of ischemic stroke. Exp Neurol 235: 326-335, 2012.

22. Kwak YD, Wang B, Li JJ, Wang R, Deng Q, Diao S, Chen Y, $\mathrm{Xu} \mathrm{R}$, Masliah E, Xu H, et al: Upregulation of the E3 ligase NEDD4-1 by oxidative stress degrades IGF-1 receptor protein in neurodegeneration. J Neurosci 32: 10971-10981, 2012.

23. Amodio N, Scrima M, Palaia L, Salman AN, Quintiero A, Franco R, Botti G, Pirozzi P, Rocco G, De Rosa N, et al: Oncogenic role of the E3 ubiquitin ligase NEDD4-1, a PTEN negative regulator, in non-small-cell lung carcinomas. Am J Pathol 177: 2622-2634, 2010.

24. Jung S, Li C, Jeong D, Lee S, Ohk J, Park M, Han S, Duan J, Kim C, Yang Y, et al: Oncogenic function of p34SEI-1 via NEDD4-1-mediated PTEN ubiquitination/degradation and activation of the PI3K/AKT pathway. Int J Oncol 43: 1587-1595, 2013.

25. Sun A, Yu G, Dou X, Yan X, Yang W and Lin Q: Nedd4-1 is an exceptional prognostic biomarker for gastric cardia adenocarcinoma and functionally associated with metastasis. Mol Cancer 13: 248, 2014.

26. Hong SW, Moon JH, Kim JS, Shin JS, Jung KA, Lee WK, Jeong SY, Hwang JJ, Lee SJ, Suh YA, et al: p34 is a nove regulator of the oncogenic behavior of NEDD4-1 and PTEN. Cell Death Differ 21: 146-160, 2014

27. Wang X, Trotman LC, Koppie T, Alimonti A, Chen Z, Gao Z, Wang J, Erdjument-Bromage H, Tempst P, Cordon-Cardo C, et al: NEDD4-1 is a proto-oncogenic ubiquitin ligase for PTEN Cell 128: 129-139, 2007.

28. Dai B, Pieper RO, Li D, Wei P, Liu M, Woo SY, Aldape KD, Sawaya R, Xie K and Huang S: FoxM1B regulates NEDD4-1 expression, leading to cellular transformation and full malignant phenotype in immortalized human astrocytes. Cancer Res 70 $2951-2961,2010$
29. Zhang H, Nie W, Zhang X, Zhang G, Li Z, Wu H, Shi Q, Chen Y, Ding Z, Zhou X, et al: NEDD4-1 regulates migration and invasion of glioma cells through CNrasGEF ubiquitination in vitro. PLoS One 8: e82789, 2013.

30. Gupta SC, Kismali G and Aggarwal BB: Curcumin, a component of turmeric: From farm to pharmacy. Biofactors 39: 2-13, 2013.

31. Kang Y, Hu W, Bai E, Zheng H, Liu Z, Wu J, Jin R, Zhao C and Liang G: Curcumin sensitizes human gastric cancer cells to 5-fluorouracil through inhibition of the NFKB survival-signaling pathway. Onco Targets Ther 9: 7373-7384, 2016.

32. Zhou X, Su J, Feng S, Wang L, Yin X, Yan J and Wang Z: Antitumor activity of curcumin is involved in down-regulation of YAP/TAZ expression in pancreatic cancer cells. Oncotarget 7: 79076-79088, 2016.

33. Zhang JR, Lu F, Lu T, Dong WH, Li P, Liu N, Ma DX and Ji CY: Inactivation of FoxM1 transcription factor contributes to curcumin-induced inhibition of survival, angiogenesis, and chemosensitivity in acute myeloid leukemia cells. J Mol Med (Berl) 92: 1319-1330, 2014.

34. Lim SO, Li CW, Xia W, Cha JH, Chan LC, Wu Y, Chang SS, Lin WC, Hsu JM, Hsu YH, et al: Deubiquitination and stabilization of PD-L1 by CSN5. Cancer Cell 30: 925-939, 2016.

35. Schönthal AH, Chen TC, Hofman FM, Louie SG and Petasis NA: Preclinical development of novel anti-glioma drugs targeting the endoplasmic reticulum stress response. Curr Pharm Des 17: 2428-2438, 2011.

36. Perry MC, Demeule M, Régina A, Moumdjian R and Béliveau R: Curcumin inhibits tumor growth and angiogenesis in glioblastoma xenografts. Mol Nutr Food Res 54: 1192-1201, 2010.

37. Sukumari-Ramesh S, Bentley JN, Laird MD, Singh N, Vender JR and Dhandapani KM: Dietary phytochemicals induce p53- and caspase-independent cell death in human neuroblastoma cells. Int J Dev Neurosci 29: 701-710, 2011.

38. Purkayastha S, Berliner A, Fernando SS, Ranasinghe B, Ray I, Tariq $\mathrm{H}$ and Banerjee P: Curcumin blocks brain tumor formation. Brain Res 1266: 130-138, 2009.

39. Choi BH, Kim CG, Bae YS, Lim Y, Lee YH and Shin SY: p21 Waf1/Cip1 expression by curcumin in U-87MG human glioma cells: Role of early growth response-1 expression. Cancer Res 68 : 1369-1377, 2008

40. Senft C, Polacin M, Priester M, Seifert V, Kögel D and Weissenberger J: The nontoxic natural compound Curcumin exerts anti-proliferative, anti-migratory, and anti-invasive properties against malignant gliomas. BMC Cancer 10: 491, 2010.

41. Wang L, Ye X, Cai X, Su J, Ma R, Yin X, Zhou X, Li H and Wang Z: Curcumin suppresses cell growth and invasion and induces apoptosis by down-regulation of Skp2 pathway in glioma cells. Oncotarget 6: 18027-18037, 2015.

42. Du WZ, Feng Y, Wang XF, Piao XY, Cui YQ, Chen LC, Lei XH, Sun X, Liu X, Wang HB, et al: Curcumin suppresses malignant glioma cells growth and induces apoptosis by inhibition of $\mathrm{SHH} /$ GLI1 signaling pathway in vitro and vivo. CNS Neurosci Ther 19: 926-936, 2013

43. Yin S, Du W, Wang F, Han B, Cui Y, Yang D, Chen H, Liu D, Liu X and Jiang C: MicroRNA-326 sensitizes human glioblastoma cells to curcumin via the SHH/GLI1 signaling pathway. Cancer Biol Ther: Nov 7, 2016 (Epub ahead of print). doi: 10.108 0/15384047.2016.1250981.

44. Li D, Xu CY, Cui RJ, Tang JB, Sun H, Yang ZK, Bu JY, Lin P, Huang N, Du YD, et al: DNA methylation inhibitor, decitabine, promotes MGC803 gastric cancer cell migration and invasion via the upregulation of NEDD4-1. Mol Med Rep 12: 8201-8208, 2015.

45. Schiborr C, Kocher A, Behnam D, Jandasek J, Toelstede S and Frank J: The oral bioavailability of curcumin from micronized powder and liquid micelles is significantly increased in healthy humans and differs between sexes. Mol Nutr Food Res 58: 516-527, 2014.

46. Micel LN, Tentler JJ, Smith PG and Eckhardt GS: Role of ubiquitin ligases and the proteasome in oncogenesis: Novel targets for anticancer therapies. J Clin Oncol 31: 1231-1238, 2013.

47. Chen $\mathrm{C}$ and Matesic LE: The Nedd4-like family of E3 ubiquitin ligases and cancer. Cancer Metastasis Rev 26: 587-604, 2007.

48. Mund T, Lewis MJ, Maslen S and Pelham HR: Peptide and small molecule inhibitors of HECT-type ubiquitin ligases. Proc Natl Acad Sci USA 111: 16736-16741, 2014. 